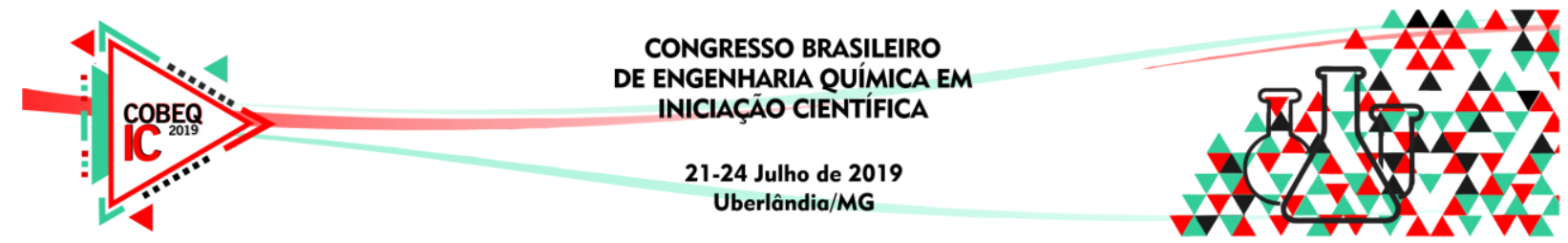

\title{
PRODUÇÃO DE CELULASES POR FERMENTAÇÃO EM ESTADO SÓLIDO A PARTIR DE RESÍDUOS AGROINDUSTRIAIS
}

\author{
V. M. OLIVEIRA ${ }^{1}$, F.M. AMBROZIM ${ }^{1}$ e I. R. PINHEIRO ${ }^{1}$ \\ ${ }^{1}$ Universidade Federal do Espírito Santo, Centro de Ciências Agrárias e Engenharias, \\ Departamento de Engenharia Rural \\ E-mail para contato: vivianemarquesolv@gmail.com
}

\begin{abstract}
RESUMO - O objetivo deste trabalho foi avaliar a produção enzimática de celulases pelo fungo filamentoso Trichoderma harzianum IOC-3844 por fermentação em estado sólido, utilizando resíduos agroindustriais. Foram realizados ensaios variando-se a umidade, tempo de fermentação e composição do meio de cultivo, a fim de avaliar a melhor condição para produzir as celulases, onde foram avaliadas como resposta a atividade CMCase das enzimas produzidas. A maior produção de CMCase $\left(23,89 \mathrm{U} \cdot \mathrm{gms}^{-1}\right)$ foi observada para a condição de 9,1\% de farelo de trigo, 35,9\% de cacau e 55\% de bagaço de cana, $81,89 \%$ de umidade e em 72 horas de cultivo.
\end{abstract}

Palavras-chave: Casca de cacau. Bagaço de cana-de-açúcar. Trichoderma harzianum.

\section{INTRODUÇÃO}

As cadeias produtivas geram uma grande quantidade de resíduo vegetal, principalmente proveniente da casca do fruto, que representam a maior parte da sua composição. Levando em consideração que os resíduos gerados se enquadram como recursos, subprodutos ou produtos secundários, muitos estudos têm sido realizados visando o seu aproveitamento de forma sustentável e economicamente viável (MÉLO, 2016).

O interesse pelas celulases nos últimos anos tem se renovado devido a seu potencial uso na conversão de biomassa em açúcares fermentescíveis, integrando assim uma nova rota para a produção de álcool combustível. Atualmente, este processo é economicamente impraticável, principalmente em razão do custo elevado das celulases. Como tecnologia promissora para a produção dessas enzimas, é possível realizar a fermentação em estado sólido (FES), o qual possui como principal característica a ausência de água livre, onde são utilizados substratos de baixo custo, como resíduos agroindustriais. Esse material sólido tem a função de atuar como suporte físico e, muitas vezes, como fonte de nutrientes para o crescimento microbiano (PANDEY,2003).

Dessa forma, o presente trabalho estudou a FES em composições diferentes de meio de cultivo. Com os substratos bagaço de cana-de-açúcar, casca de cacau e farelo de trigo o microrganismo utilizado foi o Trichoderma harzianum IOC-3844, visto que, essa espécie e suas linhagens são produtoras eficientes de enzimas celulolíticas. O objetivo foi avaliar a 


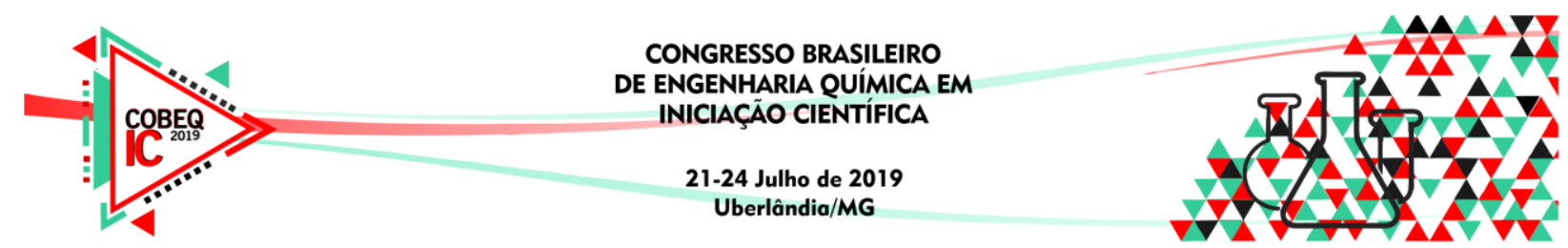

melhor composição de substratos e a influência da umidade no processo, onde foram avaliadas como resposta a atividade CMCase das enzimas produzidas.

\section{MATERIAIS E MÉTODOS}

\subsection{Cultivos Sólidos}

As fermentações foram realizadas com o fungo filamentoso Trichoderma harzianum IOC-3844, em meio sólido constituído de uma mistura de três resíduos agroindustriais: casca de cacau e bagaço de cana, os quais foram secos em estufa a $105^{\circ} \mathrm{C}$, moídos e peneirados; e farelo de trigo, sendo armazenados sob refrigeração a $-4^{\circ} \mathrm{C}$.

Em frascos Erlenmeyers de $500 \mathrm{~mL}$, foram pesadas as quantidades referentes a cada experimento, conforme a Tabela 1, totalizando $10 \mathrm{~g}$. A umidade de cada experimento foi obtida, em base úmida, pela adição de solução salina (Urbánszki, Szakacs e Tengerdy, 2000), sendo uma parte do volume adicionada antes da esterilização e outra parte utilizada para solubilizar $0,1 \mathrm{~g}$ de inóculo. Os frascos foram mantidos em estufa a $30^{\circ} \mathrm{C}$ por 120 horas, sendo que a cada 24 horas foram realizadas a determinação da umidade e a extração das enzimas.

\subsection{Extração e atividade enzimática CMCase}

Cerca de $1 \mathrm{~g}$ de sólido fermentado foi diluído em uma mistura de $20 \mathrm{~mL}$, sendo $50 \%$ água e $50 \%$ tampão citrato de sódio ( $\mathrm{pH} 4,8$ e $0,05 \mathrm{~mol} / \mathrm{L}$ ) e foi adicionado uma gota de Tween 80. Manteve-se sob agitação a $180 \mathrm{rpm}$ por 60 minutos. Após o tempo de agitação, o material foi filtrado e centrifugado a $3500 \mathrm{rpm}$ por 30 minutos, obtendo no sobrenadante o extrato enzimático.

Para a medida da atividade enzimática, foi adicionada $0,5 \mathrm{ml}$ do carboximetilcelulose (CMC) $2 \%(\mathrm{~m} / \mathrm{v})$ em tampão citrato $(\mathrm{pH} \mathrm{4,8)}$, e $0,5 \mathrm{ml}$ do extrato enzimático em tubos de ensaio, mantidos em banho-maria a $50{ }^{\circ} \mathrm{C}$ por 30 minutos. Após a reação, foram adicionados $1,5 \mathrm{ml}$ de DNS em cada tubo e estes foram colocados num banho de água fervente por 5 minutos, seguidos do banho de gelo. Posteriormente o volume foi completado com água destilada para $10 \mathrm{ml}$ e a absorbância foi lida no espectrofotômetro a 540nm (Nunes,2014; Ghose, 1987).

Neste trabalho a atividade enzimática foi expressa em U.gms ${ }^{-1}$, que é a quantidade de enzima capaz de liberar 1 micromol de açúcares redutores por minuto por grama de massa seca.

\section{RESULTADOS E DISCUSSÃO}

A Tabela 1 mostra a matriz de planejamento do projeto e a melhor produção de CMCase para cada experimento com o seu respectivo tempo de cultivo. 


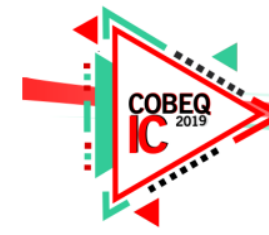

Tabela 1 - Condições dos experimentos e resultados de atividade CMCase

\begin{tabular}{|c|c|c|c|c|c|}
\hline Experimentos. & $\begin{array}{c}\text { CC } \\
(\%)\end{array}$ & $\begin{array}{c}\text { FT } \\
(\%)\end{array}$ & $\begin{array}{c}\text { BC } \\
(\%)\end{array}$ & $\begin{array}{c}\text { Umidade } \\
(\%)\end{array}$ & $\begin{array}{c}\text { CMCase máxima } \\
(\text { U/gms })\end{array}$ \\
\hline 1 & 9,1 & 9,1 & 81,8 & 58,11 & $4,65(96$ horas $)$ \\
\hline 2 & 35,9 & 9,1 & 55 & 58,11 & $4,80(72$ horas $)$ \\
\hline 3 & 9,1 & 35,9 & 55 & 58,11 & $5,98(72$ horas) \\
\hline 4 & 35,9 & 35,9 & 28,2 & 58,11 & $16,92(96$ horas) \\
\hline 5 & 9,1 & 9,1 & 81,8 & 81,89 & 18,40 (96 horas) \\
\hline 6 & 35,9 & 9,1 & 55 & 81,89 & $23,89(72$ horas) \\
\hline 7 & 9,1 & 35,9 & 55 & 81,89 & $18,28(120$ horas $)$ \\
\hline 8 & 35,9 & 35,9 & 28 & 81,89 & 11,87 (72 horas) \\
\hline 9 & 0 & 22,5 & 77,5 & 70,00 & $16,94(72$ horas) \\
\hline 10 & 45,0 & 22,5 & 32,5 & 70,00 & 12,71 (96 horas) \\
\hline 11 & 22,5 & 0 & 77,5 & 70,00 & 11,69 (48 horas) \\
\hline 12 & 22,5 & 45,0 & 32,5 & 70,00 & 11,03 (48 horas) \\
\hline 13 & 22,5 & 22,5 & 55 & 70,00 & 9,07 (96 horas) \\
\hline
\end{tabular}

CC: Casca de cacau; FT: Farelo de Trigo; BC: Bagaço de cana.

Para obter melhores resultados é importante que o meio esteja mais úmido. Observa-se que a melhor condição de fermentação atingida foi no experimento 6, em 72 horas de cultivo, atingindo uma umidade média de $83,81 \%$, o qual foi obtido uma atividade de CMCase de 23,89 U.gms ${ }^{-1}$.

Para melhor representar esse experimento, traçou a cinética de reprodução enzimática apresentada pela Figura 1.

Figura 1- Atividade enzimática CMCase em função do tempo de fermentação para o experimento 6 .

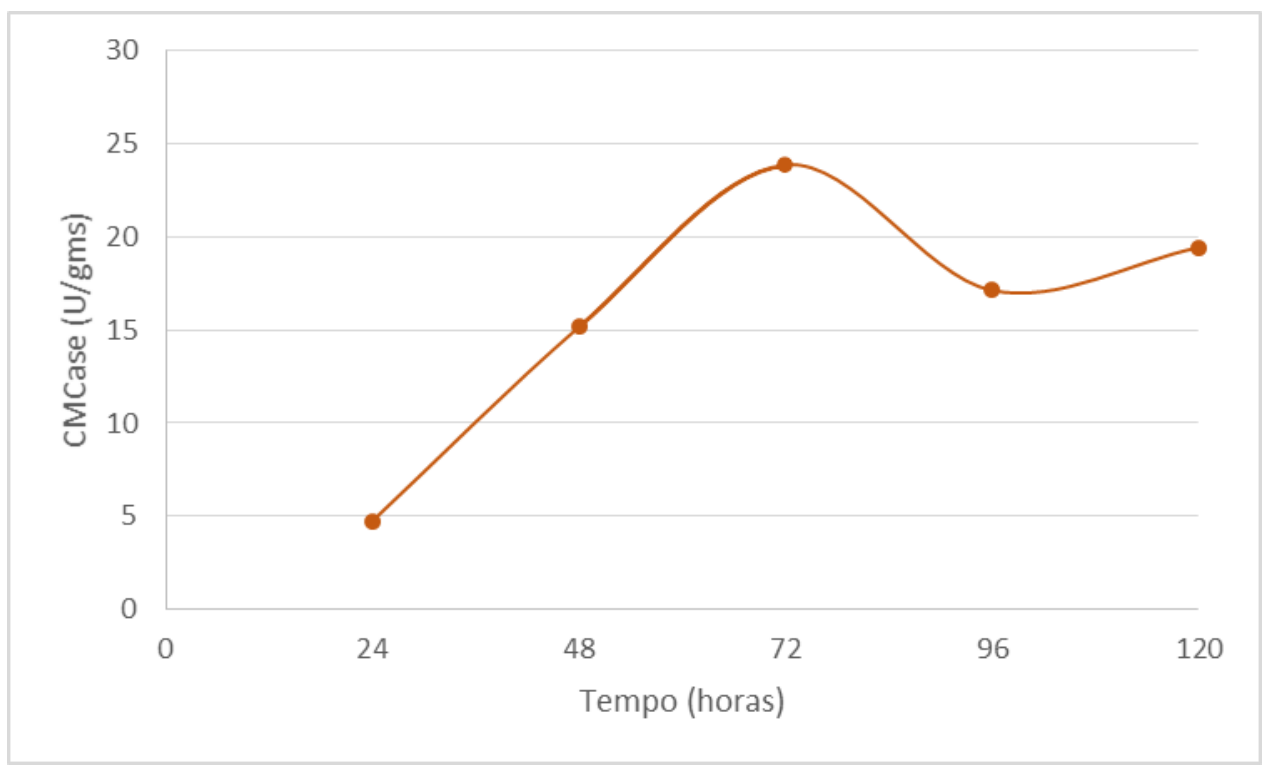




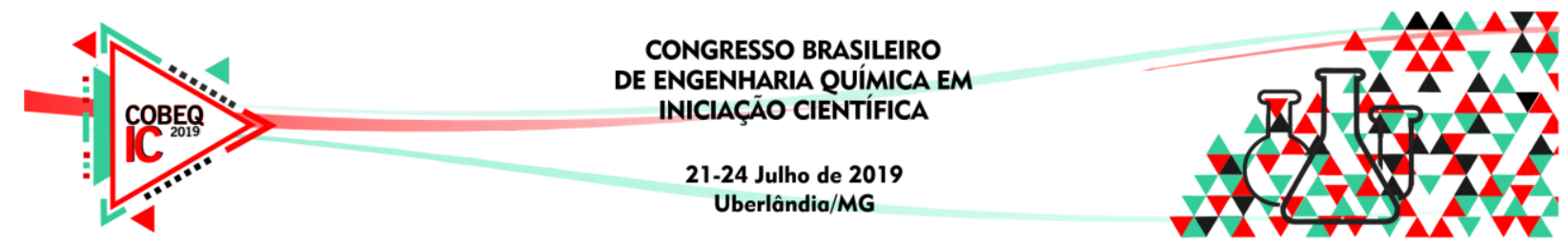

Ambrozim et al. (2018) também realizaram o estudo de fermentação em estado sólido utilizando o microrganismo Trichoderma harzianum IOC-3844 e a casca de cacau como substrato e obteve a maior atividade enzimática $\left(4,95{\left.\mathrm{U} . \mathrm{gms}^{-1}\right)}^{-1} \mathrm{em} 72\right.$ horas de cultivo, com $40 \%$ de casca de cacau, $60 \%$ de bagaço de cana e $70 \%$ de umidade. Assim, percebe-se que este trabalho encontrou valores superiores, indicando melhores condições para o crescimento microbiano e produção de celulases.

Deschamps et al. (1985) alcançaram atividade de 198 U/gms de CMCase em cultivos com BC; Rahnama et al. (2016) encontraram CMCase de 111,31 U/g de substrato, utilizando palha de arroz.

O presente estudo obteve atividades enzimáticas inferiores às encontradas na literatura, mas vale ressaltar que publicações sobre produção de celulases utilizando a mistura de resíduos agroindustriais são escassas. Dessa forma, os resultados se tornam relevantes por realizar outros experimentos visando a condição ótima do processo.

\section{CONCLUSÃO}

Os cultivos sólidos para a produção de celulases apresentaram resultados satisfatórios, o que torna a casca de cacau e o farelo de trigo bons resíduos em potencial para o uso em FES. O fungo Trichoderma harzianum se mostrou capaz de produzir as enzimas, sendo que os melhores resultados foram para umidades mais altas, atingindo o valor máximo de produção de CMCase (23,89 U.gms $\left.{ }^{-1}\right)$ no tempo de 72horas.

\section{REFERÊNCIAS}

AMBROZIM, F. M. et al. Estudo da Utilização da Casca de Cacau na Fermentação em Estado Sólido para produção de celulases com T. harzianum. In: Congresso Brasileiro de Engenharia Química, 22, 2018, São Paulo. Anais... São Paulo: Associação Brasileira de Engenharia Química, 2018.

DESCHAMPS F et al. Cellulase production by Trichoderma harzianum in static and mixed solid-state fermentation reactors under nonaseptic conditions. Biotechnol Bioeng. 1985.

GHOSE TK. Measurement of cellulase activities. Pure App. Chem., v. 59, n. 2, 1987.

MÉLO, B. C. A. Produção de Celulases por Fermentação em Estado Sólido em Resíduo de Acerola (Malpighia sp.) Utilizando Trichoderma reesei. 2017. 116 f. Tese (Doutorado) - Curso de Engenharia de Alimentos, Universidade Federal de Santa Catarina, Florianópolis, 2016.

NUNES, J. M. N. Produção de Enzimas Celulolíticas por Linhagens do Fungo Trichoderma. 2014. 37 f. TCC (Graduação) - Curso de Engenharia Química, Departamento da Engenharia Rural, Universidade Federal do Espírito Santo, Alegre, 2014.

PANDEY, A. Solid-state fermentation. Biochemical Engineering Journal. v. 13, p. 81-84, 2003. 


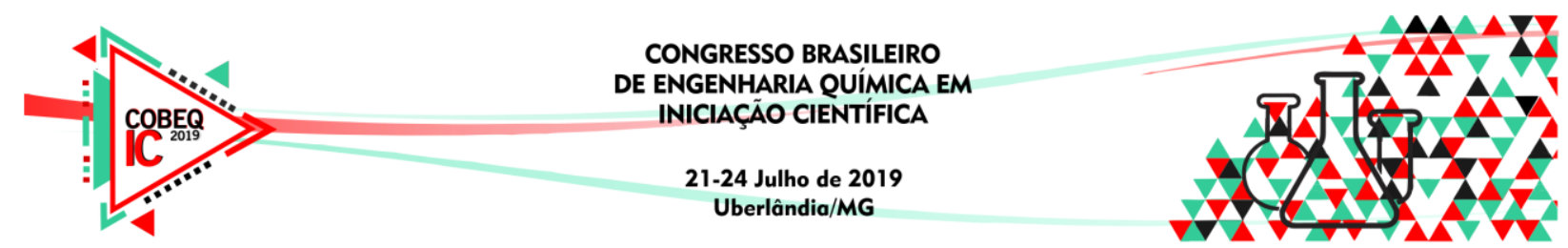

RAHNAMA $\mathrm{N}$ et al. Production and characterisation of cellulase from solid state fermentation of rice straw by Trichoderma harzianum SNRS3. Pertanika J. Trop. Agric. Sci. 39 (4). 2016.

URBÁNSZKI K, SZAKACS G, TENGERDY RP. Standardization of the filter paper activity assay for solid sbubstrate fermentation. Biotechnol. Lett. 22. 2000. 